\title{
PARTISIPASI MASYARAKAT DALAM PENGELOLAAN EKOWISATA HUTAN MANGROVE DI KAMPUNG RAWA MEKAR JAYA
}

\author{
Nuraisah \& Lilis Wahyuni \\ Program Studi Ilmu Administrasi Negara Sekolah Tinggi Ilmu Administrasi Lancang Kuning Dumai \\ Email: \\ aisahnur067@gmail.com
}

\begin{abstract}
ABSTRAK
Penelitian tentang pengelolaan mangrove berbasis partisipasi masyarakat di kampung Rawa Mekar Jaya. Tujuan untuk: (1) mendeskripsikan jenis partisipasi masyarakat di kampung Rawa Mekar Jaya. (2) mendeskripsikan faktor penghambat partisipasi masyrakat dalam pengelolaan mangrove di kampung Rawa Mekar Jaya. Teknik pengumpulan data meliputi wawancara, observasi dan dokumentasi, sedangkan analisis data menggunakan teknik deskriptif kualitatif. Berdasarkan hasil penelitian, masyarakat kampung Rawa Mekar Jaya awalnya tidak memiliki inisiatif untuk memulai program pembangunan dan pengembangan mangrove. Tetapi ada seorang agent of change tokoh pemuda yang mengajak masyarakat untuk peduli akan mangrove baik untuk menjaga, merawat, membersihkan dan melakukan pembibitan mangrove serta meyakinkan masyarakat bahwa dengan dijadikan mangrove ini sebagai tempat ekowisata akan memberikan perubahan bagi kampung mereka. Masyarakat kampung Rawa Mekar Jaya dalam pelaksanaan pembangunan ekowisata hanya sebagian saja yang ikut bergotong royong melakukan pembersihan di area mangrove dan pembersihan jalan menuju mangrove. Masyarakat Kampung Mekar jaya sebagian ada yang membantu pekerjaan pembangunan mangrove dengan membantu membangun tempat duduk dibeberapa titik tertentu disepanjang area mangrove. Dalam pengelolaan dan pengembangan mangrove Kampung Rawa Mekar Jaya masih terdapat kendala sehingga belum dapat memberikan manfaat yang optimal. Hambatan yang di hadapi oleh masyarakat yakni, keterbatasan pengetahuan masyarakat kampung Rawa Mekar Jaya dalam memanfaatkan potensi ekowisata magrove yang telah ada.
\end{abstract}

Kata Kunci: Partisipasi masyarakat, pengelolaan, mangrove, kampung.

\begin{abstract}
Research on mangrove management based on community participation in the village of Rawa Mekar Jaya. Objectives to: (1) describe the types of community participation in the Rawa Mekar Jaya village. (2) describe the factors inhibiting community participation in mangrove management in Rawa Mekar Jaya village. Data collection techniques include interviews, observation and documentation, while data analysis uses descriptive qualitative techniques. Based on the research results, the Rawa Mekar Jaya village community initially did not have the initiative to start the mangrove development and development program. But there is an agent of change of a youth leader who invites the community to care about mangroves both to maintain, care for, cleanse and nursery mangroves and to convince the community that by making this mangrove as an ecotourism place will bring change to their village. In the Rawa Mekar Jaya village community, in the implementation of ecotourism development, only a portion of them worked together to clean the mangrove area and clean the road to the mangrove. Some of the community of Kampung Mekar jaya are assisting the work of mangrove development by helping to build a seat at certain points along the mangrove area. In managing and developing mangroves in Rawa Mekar Jaya Village there are still obstacles so that they cannot provide optimal benefits. The obstacle faced by the community is the limited knowledge of the people of Rawa Mekar Jaya village in utilizing the potential of existing magrove ecotourism.
\end{abstract}

Keywords: Community participation, management, mangroves, villages. 


\section{PENDAHULUAN}

Indonesia memiliki kawasan pesisir yang begitu luas dan berada di urutan keempat di dunia dengan garis pantai terpanjang. Wilayah ini merupakan tempat menumpuknya berbagai bahan buangan, baik berasal dari hulu maupun daerah setempat, akibat berbagai macam aktivitas manusia (Robert Siburian dan John Haba, 2016:1). Wilayah pesisir terdiri dari berbagai ekosistem salah satunya adalah ekosistem hutan mangrove (Robert Siburian dan John Haba, 2016:2).

Ekowisata hutan mangrove merupakan ekosistem utama pendukung kehidupan wilayah peisir. Hutan mangrove memiliki peran ekologis, antara lain sebagai penyedia nutrein bagi biodata perairan, tempat pemijahan, dan asuhan (nursery ground) bagi bermacam biota, dan penahan abrasi pantai (Departemen Kehutanan dalam Haikal Hilman Fahrian et al 2015).

Kampung Rawa Mekar Jaya yang merupakan kampung yang terletak di wilayah pesisir. Kampung ini memiliki potensi yang besar di bidang ekowisata mangrove. Namun, sebelum dikenal sebagai tumbuhan ekowisata yang memberi manfaat (potensi). Mangrove hanya dianggap sebagai pohon biasa bagi masyarakat kampung Rawa Mekar jaya yang gunakan sebagai bahan kayu bakar, arang, area mencari siput. Dan ada sebagian dari masyarakat yang takut datang ke mangrove karena mempersepsikan suatu unsur mistis yang mereka dengar dari leluhur mereka terdahulu, belum lagi ada yang beberapa orang tua yang melarang anak untuk pergi ke mangrove karena dianggap ada hewan berbahaya seperti ular dan buaya yang hidup di mangrove tersebut.

Mangrove yang selama ini hanya di anggap penahan abrasi pantai dan pohon biasa ternyata dapat memberi dampak yang lebih yakni dengan dikembangkan menjadi ekowisata yang memberikan nilai edukasi baik pada masyarakat, maupun wisatawan, nilai social-budaya masyarakat terangkat, dan menjadi nilai tambah ekonomi bagi masyarakat. Harapannya dengan adanya ekowisata mangrove kesejateraan masyarakat setempat meningkat. Menurut Hidayanti dkk dalam Reydi
Marco Manahampi et al (2015) ekowisata diharapkan dapat membuka peluang bagi berkembangnya usaha kecil yang sesuai dengan skala lokasi tersebut. Oleh karena itu ada batasan yang sedikit kuat untuk ekowisata di mana secara ekonomi dan ekologi berpengaruh positif maka dibutuhkan adanya dukungan pemerintah dalam bentuk kebijakan yang memberi batasan akan pariwisata alam yang bertanggungjawab dan memberi manfaat secara ekonomi dan ekologi. Ekowisata dianggap mampu menjambatani jurang antar pengunjung, tempat tujuan wisata, operator, pemerintah dan lingkungan menjadi satu visi konservasi sebagai suatu gerakan global.

Agar ekowisata terus eksis memberikan manfaat bagi masyarakat dan wisatawan, maka perlu dilakukan pengembangan ekowisata berkelanjutan yang bertujuan mewujudkan pembangunan wilayah pesisir yang memenuhi harapan dan kepuasan wisatawan sehingga bisa mendongrak ekonomi masyrakat pesisir. Menurut Tuwo dalam Hertati (2017) pengembangan ekowisata merupakan salah satu alternatif pembangunan yang dapat membantu mengatasi masalah agar menghasilkan nilai tambah yang nyata dan positif bagi kegiatan konservasi lingkungan dan budaya setempat sehingga dapat meningkatkan kesejahteraan masyarakat. Pengembangan kawasan ekowisata sebagian besar didukung oleh harapan akan aspek ekonomi, sehingga menjadi salah satu motif bagi masyarakat untuk terlibat dalam pengembangan kawasan tersebut (Adelia dalam Amar Maruf et a/2018).

Sementara itu, J. Stephen, Page \& Dowling K. Ross dalam Lia dkk (2017) mengeloborasi mengenai konsep dasar ekowisata menjadi lima prinsip inti, termasuk yang berbasis alam, berkelanjutan secara ekologis, lingkungan edukatif, lokal wisatawan serta bermanfaat serta menghasilkan kepuasan; a)Nature based (berbasis alam), b)Pengembangan ekowisata didasarkan pada lingkungan alam dengan fokus pada lingkungan biolagi, fisik dan budaya, c)Ecologically sustainable (berlanjutan secara ekologis), d)Ecotourism dapat memberikan acuan terhadap pariwisata secara keseluruhan dan dapat membuat ekologi yang 
berkesinambungan, educative (pendidikan lingkungan), f)Pengembangan ekowisata harus mengandung usnur pendidikan atau perilaku seseorang menjadi memilki kepedulian, tanggung jawab dan komitmen terhadap pelestarian lingkungan, g)Locally beneficial (manfaat bagi masyarakat lokal), h)Pengembangan ecotourism harus dapat menciptakan keuntungan yang nyata bagi masyarakat sekitar. Pengembangan harus didasarkan atas musyawarah dan persetujuan masyarakat setempat serta peka dan menghormati nilai-nilai sosial budaya serta tradisi keagamaan yang dianut masyarakat di sekitar kawasan, i)Generates tourist satisfaction (menghasilkan kepuasan wisatawan, j)Pengembangan ekowisata harus mampu memberikan kepuasan pengalaman kepada pengunjung untuk memastikan usaha ekowisata dapat berkelanjutan.

Partisipasi masyarakat dalam pengelolaan mangrove perlu ditingkatkan melalui kesadaran masyarakat akan pentingnya lingkungan yang edukatif, hijau, bersih dan menguatkan inisiatif masyarakat dalam menjaga, memelihara dan meningkatkan fungsi lingkungan hidup. Disamping itu, kemampuan masyarakat berkontribusi dalam pengembangan ekowisata mangrove juga akan berpengaruh pada pendapatan masyarakat, khususnya di lingkungan Rawa Mekar Jaya, Kabupaten Siak. Kondisi Keadaan Kampung Rawa Mekar Jaya adalah merupakan bagian dari Kabupaten Siak yang posisi lokasinya terletak di kecamatan Sungai Apit yaitu perbatasan sebelah barat dengan kampung Sungai Rawa, sebelah utara dengan desa Lukit, sebelah selatan dengan desa Dayun dan sebelah timur dengan kampung Penyengat. Luas wilayah + $16.803 \mathrm{HA}$ m2, berpenduduk 269 KK (1010 Jiwa). Pria sebanyak 520 Jiwa dan wanita sebanyak 490 jiwa.

\section{Partisipasi masyarakat dapat} ditumbuhkan dari berbagai pihak salah satunya aparat kampung yang menjadi kunci keberhasilan suatu kegiatan ataupun program pengembangan ekowisata. Menurut Sumardi dan Evers dalam Sulistiyorini dkk (2015), partisipasi adalah ikut sertanya suatu kesatuan untuk mengambil bagian dalam aktivitas yang dilaksanakan oleh susunan kesatuan yang lebih besar dari masyarakat dapat diartikan sebagai keikutsertaan masyarakat dalam suatu kegiatan bersama sesuai dengan kemampuannya masing-masing untuk menunjang pencapaian tujuan tertentu tanpa mengorbankan kepentingan diri sendiri. Lebih dari itu, partisipasi berkaitan dengan tiga hal yakni mental and emotional involvement

(keterlibatan mental dan emosi), motivation to contribute (dorongan untuk memberikan sumbangan), dan acceptance of responsibility (penerimaan tanggung jawab) sebagaimana diungkapkan (Davis Hurairah, Jurnal Sosial, 2012).

Untuk mengetahui bentuk partisipasi masyarakat dalam pengelolaan ekowisata mangrove di wilayah tersebut, maka perlu di lakukan penelitian secara mendalam.

\section{METODE PENULISAN}

Metode yang digunakan dalam penulisan karya tulis ilmiah ini adalah metode penelitian deskriptif. Metode yang digunakan untuk mengumpulkan data adalah metode studi pustaka yang terdiri atas pencarian data dan informasi melalui dokumen-dokumen pendukung berupa data dari buku, jurnal ilmiah, dan dokumen elektronik dari internet. Adapun tahapan dalam penulisan diantaranya perumusan masalah untuk kemudian menjadi gagasan, pengumpulan data dan fakta terkait, verifikasi data dan fakta, analisa konseptual dengan argumentasi yang rasional, perumusan hasil gagasan dan kesimpulan serta rekomendasi terkait

penanganan masalah.

\section{TELAAH PUSTAKA}

\section{Partisipasi}

Menurut Syahyuti (2006:154) partisipasi adalah proses tumbuhnya kesadaran terhadap saling hubungan antara kelompok-kelompok sosial dan komunitas dengan mengambil kebijakan dan lembaga-lembaga jasa lain, partisipasi dapat didefenisikan sebagai proses dimana seluruh pihak dapat membentuk dan terlibat dalam seluruh inisiatif program dan kegiatan. Partisipasi dapat juga didefenisikan 
kesediaan membantu berhasilnya program sesuai dengan kemampuan setiap orang tanpa berarti harus mengorbankan kepentingan sendiri. (Keith Davis dalam Selinaswati 2017).

Partisipasi merupakan aktivitas yang terintegrasi dalam diri tiap-tiap individu di dalamnya terdapat proses penekanan terhadap stimulus yang diterima atau dirasakan oleh alat indera individu dan proses ini selalu berlangsung setiap saat, karena dalam partisipasi itu merupakan

aktivitas yang terintergrasi, maka seluruh yang ada dalam diri individu seperti perasaan, pengalaman,

kemampuan berpikir, kerangka acuan, dan aspek-aspek lain yang ada dalam diri individu akan ikut berperan dalam persepsi tersebut (Walgito dalam Ahmad Nawawi 2013).

Partisipasi juga dimaknai sebagai keterlibatan orang secara sukarela tanpa tekanan dan jauh dari perintah, sebagai mana diungkapkan oleh Koentjaraningrat dalam Solekhan (2014:112) bahwa partisipasi masyarakat dalam pelaksanaan pembangunan lebih menekankan kepada kemauan sendiri secara sadar untuk melaksanakan aktifitasaktifitas pembangunan melalui swadaya gotong royong maupun sumbangan sukarela.

Menurut Santosa dalam Sulistiyorini (2015:73) bahwa : "Partisipasi didefinisikan sebagai karakteristik mental/pikiran dan emosi/perasaan seseorang dalam situasi kelompok yang mendorongnya untuk memberikan sumbangan kepada kelompok dalam usaha mencapai tujuan serta turut bertanggung jawab terhadap usaha yang bersangkutan."

\section{Partisipasi Masyarakat}

Menurut Isbandi (2007:27) partisipasi masyarakat adalah keikutsertaan masyarakat dalam proses pengidentifikasian masalah dan potensi yang ada di masyarakat, pemilihan dan pengambilan keputusan tentang alternatif solusi untuk menangani masalah, pelaksanaan upaya mengatasi masalah, dan ketertiban masyarakat dalam proses mengevaluasi perubahan yang terjadi.

Esmara dalam Solekhan (2014:112) bahwa partisipasi masyarakat dalam pelaksanaan pembangunan berhubungan dengan dana, fasilitas, dan tenaga dari masyarakat itu sendiri, serta kemampuan serta untuk penyelenggaraan administrasi termasuk kodinasi secara teratur dari setiap program pembangunan.

\section{Bentuk-Bentuk Partisipasi Masyarakat}

Menurut Mardikanto (2014:200) bentuk-bentuk partisipasi yang dilakukan oleh setiap warga masyarakat dapat berupa:

1. Menjadi anggota kelompok-kelompok masyarakat.

2. Melibatkan diri pada kegiatan diskusi kelompok.

3. Melibatkan diri pada kegiatan-kegiatan organisasi untuk menggerakkan partisipasi masyarakat yang lain.

4. Menggerakkan sumberdaya masyarakat.

5. Mengambil bagian dalam proses pengambilan keputusan.

6. Memanfaatkan hasil-hasil yang di capai dari kegiatan masyarakatnya.

Menurut Cohen dan Uphoff dalam Dwiningrum (2015:61) membedakan partisipasi menjadi empat jenis, yaitu :

1. Partisipasi dalam pengambilan keputusan.

- keterlibatan masyarakat dalam menyampaikan aspirasi dalam rapat tentang pembangunan ekowisata.

- keterlibatan masyarakat dalam menetapkan rencana pengelolaan ekowisata

2. Partisipasi dalam pelaksanaan.

- Keinginan Masyarakat untuk ikut serta bergotong royong dalam pelaksanaan pengelolaan ekowisata.

- keinginan masyarakat untuk ikut membantu pekerjaan pembangunan dan pengelolaan ekowisata.

- keinginan masyarakat untuk memberikan sumbangan tenaga dan alat dalam kegiatan pembangunan dan pengelolaan ekowisata

3. Partisipasi dalam pengambilan pemanfaatan. Dan 


\begin{tabular}{|c|c|c|c|c|}
\hline Share: Social Work Jurnal & VOLUME: 10 & NOMOR: 1 & HALAMAN: 73- 82 & $\begin{array}{c}\text { ISSN: 2339-0042 (p) } \\
\text { ISSN: 2528-1577 (e) } \\
\text { DOI: } 10.24198 / \text { share.v10i1.26896 }\end{array}$ \\
\hline
\end{tabular}

- kesadaran masyarakat untuk mengoptimalkan hasil-hasil pembangunan ekowisata mangrove.

- kesadaran masyarakat untuk memelihara hasil pembangunan mangrove

- masyarakat dapat memanfaatkan hasil pembangunan mangrove yang dilakukan di kampung

4. Partisipasi dalam evaluasi.

- evaluasi oleh Kepala Kampung dan masyarakat terhadap hasil pembangunan yang ada.

- keterlibatan masyarakat secara bersama dalam mengawasi pelaksanaan kegiatan pembangunan

- pengumpulan informasi yang berkaitan dengan perkembangan kegiatan pembangunan yang telah dilaksanakan

Dilihat dari tingkatan atau tahapan partisispasi Wilcox dalam Mardikanto (2013:86) mengemukakan adanya 5 (lima) tingkatan yaitu:

1. Memberikan informasi (information).

2. Kosultasi (consultation), yaitu menawarkan pendapat, sebagai pendengar yang baik untuk memberikan umpan balik, tetapi tidak terlibat dalam implementasi ide dan gagasan, pilihanpilihan serta menembangkan peluang yang diperlukan guna mengambil keputusan.

3. Bertindak bersama (acting together) dalam arti tidak sekedar ikut dalam mengambil keputusan, tetapi juga terlibat dan menjallin kemitraan dalam pelaksanaan kegiatannya.

4. Memberikan dukungan (supporting independent community interest) dimana kelompok-kelompok local menawarkan pendanaan, nasehat, dan dukungan lain untuk mengembangkan agenda kegiatan.

5. Memberikan dukungan (supporting independent community interest) dimana kelompok-kelompok lokal menawarkan pendanaan, nasehat dan dukungan lain untuk pengembangan agenda kegiatan.

\section{Ekowisata}

Istilah "ekowisata" dapat diartikan sebagai perjalanan oleh seorang turis ke daerah terpencil dengan tujuan menikmati dan mempelajari mengenai alam, sejarah dan budaya suatu daerah. Di mana pola wisatanya membantu ekonomi masyarakat lokal dan mendukung pelestarian alam (Hertanto dalam Reydi Marco Manahampi et al 2015). Selanjutnya menurut Satria dalam Amar Maruf et al (2018) ekowisata merupakan bentuk perjalanan wisata ke suatu lingkungan baik yang alami, buatan, ataupun yang memiliki kekhasan budaya yang bersifat informatif dan partisipatif, yang bertujuan untuk menjamin kelestarian alam dan fungsi sosial budaya. Ekowisata menitikberatkan pada tiga hal utama, yaitu keberlangsungan alam dan ekologi, keberlanjutan ekonomi dan secara psikologi memastikan tingkat penerimaan dalam kehidupan sosial masyarakat. Sedangkan menurut pendapat Damamik dan Weber dalam Bagus Nugraha dkk (2015) ekowisata adalah suatu kegiatan wisata yang bertanggungjawab terhadap lingkungan yang umumnya dilakukan pada daerah yang masih alami. Selain untuk menikmati keindahan alam, ekowisata juga melibatkan unsur pendidikan, pemahaman serta dukungan terhadap upayaupaya konservasi alam dan meningkatkan perekonomian masyarakat setempat.

From dalam Selinaswati (2017:85) menjelaskan tiga konsep dasar yang lebih operasional tentang ekowisata yaitu sebagai berikut:7 1) perjalanan Outdoor dan dikawasan alam yang tidak menimbulkan kerusakan lingkungan. 2) Wisata ini mengutamakan penggunaan fasilitas transportasi yang diciptakan dan dikelola masyarakat kawasan wisata tersebut. Prinsipnya akomodasi yang tersedia bukanlah perpanjangan tangan hotel Internasional dan makanan yang ditawarkan bukan makanan yang berbahan baku impor, melainkan semuanya berbasis produk lokal. Dengan demikian memberikan keuntungan langsung bagi masyarakat lokal. 3) Perjalanan wisata menaruh perhatian besar pada lingkungan alam dan budaya lokal. Para 


\begin{tabular}{|c|c|c|c|c|}
\hline Share: Social Work Jurnal & VOLUME: 10 & NOMOR: 1 & HALAMAN: $73-82$ & $\begin{array}{c}\text { ISSN: 2339-0042 (p) } \\
\text { ISSN: 2528-1577 (e) } \\
\text { DOI: } 10.24198 / \text { share.v10i1.26896 }\end{array}$ \\
\hline
\end{tabular}

wisatawan banyak belajar dari masyarakat lokal.

\section{Mangrove}

Menurut Mulyadi dan Fitriani dalam Askasifi Eka Cesario dkk 2015 hutan mangrove adalah hutan yang tumbuh di muara sungai, daerah pasang surut atau tepi laut. Tumbuhan mangrove bersifat unik karena gabungan dari ciri-ciri tumbuhan yang hidup di darat dan di laut. Sedangkan Began dalam Sarwo Edy Saputra dan Agus Setiawan (2017) menyatakan hutan mangrove merupakan komoditas vegetasi pantai tropis yang di dominasi oleh beberapa jenis pohon mangrove yang mampu tumbuh dan berkembang pada daerah pasang surut pantai berlumpur.

\section{Community Development}

Dalam pekerja sosial pengembangan masyarakat adalah metode yang bertujuan untuk memperbaiki kualitas hidup masyarakat melalui penggunaan sumber-sumber yang ada pada mereka serta menekankan pada partisipasi sosial (Suharto,2009: 37).

Konsep pengembangan masyarakat (Community Development) sebenarnya adalah pengorganisasian Masyarakat (Community Organization), yang bermakna mengorganisasikan masyarakat sebagai sebuah sistem untuk melayani warganya dalam setting kondisi yang berubah. Dengan demikian inti pengertiannya adalah mendorong warga masyarakat untuk mengorganisasikan diri untuk melaksanakan kegiatan guna mencapai kesejahteraannya sendiri. (Budhi Wibhawa dkk, Dasar-dasar Pekerjaan Sosial, 2010:109).

$$
\text { Menurut Sulistiyorini 2015:77 }
$$

Pengembangan masyarakat diselenggarakan dengan tujuan untuk mencapai kondisi masyarakat dimana transformasi sosialbudaya, politik, ekonomi, teknologi, dapat dilaksanakan oleh masyarakat secara berkelanjutan. Ada tiga karakter umum program pengembangan mayarakat, yaitu:

1. Berbasis masyarakat (communitybase) atau masyarakat sebagai pelaku utama atau subyek dalam perencanaan dan pelaksanaan program
2. Berbasis sumberdaya setempat (local resources-base), yaitu penciptaan

kegiatan dengan melihat potensi sumberdaya (alam, manusia) yang ada.

3. Berkelanjutan (sustainable) yaitu program berfungsi sebagai penggerak awal pembangunan yang berkelanjutan.

\section{Hasil Dan Pembahasan}

Menurut Cohen dan Uphoff dalam Dwiningrum (2015:61) membedakan partisipasi menjadi empat jenis, yaitu:

1. Partisipasi dalam pengambilan keputusan.

- keterlibatan masyarakat dalam menyampaikan aspirasi dalam rapat tentang pembangunan ekowisata. Masyarakat kampung Rawa Mekar Jaya awalnya tidak memiliki inisiatif untuk memulai program pembangunan dan pengembangan mangrove. Tetapi ada seorang agent of change tokoh pemuda yang mengajak masyarakat untuk peduli akan mangrove baik untuk menjaga, merawat, membersihkan dan melakukan pembibitan mangrove serta meyakinkan masyarakat bahwa dengan dijadikan mangrove ini sebagai tempat ekowisata akan memberikan perubahan bagi kampung mereka. Dari situlah masyarakat sudah ikut peduli dengan melakukan berbagai upaya untuk memperindah mangrove untuk menarik minat wisatawan walaupun tidak semuanya ikut berpartispasi, hanya sebagian saja, sudah memberikan enegri yang positif.

- keterlibatan masyarakat dalam menetapkan rencana pembangunan dan pegembangan ekowisata mangrove

2. Partisipasi dalam pelaksanaan.

- keinginan masyarakat untuk ikut serta bergotong royong dalam pelaksanaan pembangunan dan pengembangan ekowisata. Masyarakat kampung Rawa Mekar Jaya dalam pelaksanaan pembangunan ekowisata hanya sebagian saja yang ikut bergotong royong melakukan pembersihan di area 
mangrove dan pemberihan jalan menuju mangrove.

- keinginan masyarakat untuk ikut membantu pekerjaan pembangunan ekowisata. Masyakat kampung Rawa Mekar jaya sebagian ada yang membantu pekerjaan pembangunan mangrove dengan membantu membangun tempat duduk dibeberapa titik tertentu disepanjang area mangrove agar pengunjung bisa beristirahat. Dan membuat dekorasi yang unik untuk menarik pengunjung yang minat akan fotografi.

- keinginan masyarakat untuk memberikan sumbangan tenaga dan alat dalam kegiatan pembangunan ekowisata.

3. Partisipasi dalam pengambilan pemanfaatan.

- kesadaran masyarakat untuk mengoptimalkan hasil-hasil pembangunan ekowisata mangrove.

- kesadaran masyarakat untuk memelihara hasil pembangunan mangrove

- masyarakat dapat memanfaatkan hasil pembangunan mangrove yang dilakukan di kampung

4. Partisipasi dalam evaluasi.

- evaluasi oleh Kepala Kampung dan masyarakat terhadap hasil pembangunan yang ada.

- keterlibatan masyarakat secara bersama dalam mengawasi pelaksanaan kegiatan pembangunan

- pengumpulan informasi yang berkaitan dengan perkembangan kegiatan pembangunan yang telah dilaksanakan. Dalam pengelolaan dan pengembangan mangrove Kampung Rawa Mekar Jaya masih terdapat kendala sehingga belum dapat memberikan manfaat yang optimal. Hambatan yang di hadapi oleh masyarakat yakni, keterbatasan pengetahuan masyarakat kampung Rawa Mekar Jaya dalam memanfaatkan potensi ekowisata magrove yang telah ada, hal ini terlihat dari belum tersedianya fasilitas rumah makan padahal wisatawan yang berkunjung membutuhkan makanan apalagi wisatawan dari luar daerah dan mancanegara hal ini seharusnya masyarakat bisa membuka rumah makanan dengan kuliner khas laut dan sungai dengan olahan masakan Melayu seperti asam pedas ikan kakap atau lele, gulai siput, sambal tanak udang dengan begitu ekonomi masyarakat terangkat, selanjutnya belum tersedianya tempat menginap dengan menyediakan penginapan, hal ini bisa memberikan nilai ekonomis yang tinggi apabila di patok dengan harga yang bersahabat, karena sebagian besar wisatawan membutuhkan tempat penginapan atau masyarakat dapat menyediakan kamar kosong yang bisa di tempati wisatawan, selanjutnya belum tersedianya pelatihan budidaya mangrove dengan menyediakan pendidikan dan pelatihan membudaya menanam mangrove bisa menumbuh kesadaran dan kepedulian wisatawan akan lingkungan, lalu belum tersedianya tour guide padahal bisa memanfaatkan dari putra daerah setempat dengan memberikan pelatihan khusus bahasa yang nantinya dapat memandu wisatawan mancanegra, belum tersedianya aneka olahan makanan dari mangrove seharusnya masyarakat bisa membuat jus tematu dari pohon nipah yang bisa diperoleh disepanjang sungai, lalu membuat sirup dan dodol dari buah mangrove, dan masih belum tersedia tempat menarik untuk fotografi tempat berfoto berpengaruh terhadap ambsisi bagi wisatawan lokal dan mancanegara untuk berkunjung di kawasan mangrove misalnya wisatawan lokal generasi muda suka ala $k-p o p$, japaness, barat masyarakat bisa menyedikan tempat foto dengan ciri itu, papan foto dengan bahasa tersebut dan untuk wisatawan asing masyarakat bisa memperkenalkan budaya Melayu, menyediakan tempat foto dengan pemandangan menarik di area matahari terbenam dan terbit bagi pemburu sunset, menyediakan lampu warna-warni di malam hari di area mangrove dan pohon mangrove, selanjutnya masih kurang promosi oleh masyrakat. Padahal saat ini era teknologi informasi dan maraknya media sosial masyarakat bisa melakukan promosi melalui facebook, instagram, youtube dengan melakukan editing yang menarik dan bisa melalui unggahan tulisan di website. 
Hal itu membuat peneliti melakukan wawancara dengan beberapa informan pada 23 agustus 2019 di wilayah area mangrove, narasumber memberikan berbagai persepsi yang beragam mengenai pengelolaan dan pemanfaatan ekowisata. Narasumber pertama tidak berminat melakukan usaha kuliner karena merasa tidak mempunyai bakat dan takut rugi. Diwaktu yang bersamaan peneliti menemukan Narasumber yang kedua, sebelumnya narasumber ini menolak saat peneliti bertanya kesan terhadap ekowisata mangrove. Narasumber menyuruh peneliti untuk bertanya kepada orang lain saja. Namun peneliti memberikan klarifikasi hanya sebentar dan hanya untuk memenuhi tugas akhirnya narasumber mau namun jawaban yang peneliti dapatkan "saya suka dengan adanya ekowisata ini, tapi dengan banyaknya orang yang datang berkunjung dikampung ini, persaingan akan semakin berat apalagi mereka lebih maju, jika nanti mereka berminat membuat usaha disini maka masyarakat disini ekonominya semakin terpuruk. Berbeda dengan narasumber yang ketiga berbeda saat peneliti bertanya minat mengelola mangrove dengan membangun homestay, narasumber berminat hanya saja kendala dibiaya dalam membangun homestay membuat narasumber mengubur impian itu.

Dari hal tersebut seharusnya masyarakat diberikan pemahaman dalam bentuk sosialisasi kepada masyarakat dari instasi terkait, agar masyarakat dapat pengetahuan dan lalu diperkuat dengan pelatihan dalam memanfaatkan, mengelola dan mempromosikan dan memberikan bantuan modal bagi masyarakat yang berminat untuk berinovasi yang nantinya bisa mendukung kerjasama yang baik antar masyarakat dan instansi pemerintah sehingga dapat mencapai tujuan ekowisata yang memberi kesejahteraan masyarakat. sebagai salah satu objek wisata daratan.

Pemanfaatan potensi kawasan mangrove perlu dikelola dengan baik. Pengelolaan lingkungan kawasan mangrove merupakan upaya dalam mendukung pengembangan wilayah pesisir secara optimal, bijaksana dan bertanggung jawab, tentunya dengan melibatkan partisipasi masyarakat dan berbagai pihak yang terkait serta tetap memperhatikan daya dukung lingkungannya. (Erawati dalam Rohman dkk 2016). Partisipsi masyarakat diperlukan dalam pengembangan ekowisata mangrove, agar masyarakat juga merasakan dampak positif dari ekowisata tersebut. Pengelolaan sumber daya alam pesisir pada hakekatnya adalah suatu proses pengontrolan tindakan manusia atau masyarakat di sekitar kawasan pesisir agar pemanfaatan sumber daya alam dapat dilakukan secara bijaksana dengan mengindahkan kaidah kelestarian lingkungan (Supriharyono dalam Purnamasari dkk 2015).

\section{KESIMPULAN}

Masyarakat kampung Rawa Mekar Jaya awalnya tidak memiliki inisiatif untuk memulai program pembangunan dan pengembangan mangrove. Tetapi ada seorang agent of change tokoh pemuda yang mengajak masyarakat untuk peduli akan mangrove baik untuk menjaga, merawat, membersihkan dan melakukan pembibitan mangrove serta meyakinkan masyarakat bahwa dengan dijadikan mangrove ini sebagai tempat ekowisata akan memberikan perubahan bagi kampung mereka.

Masyarakat kampung Rawa Mekar Jaya dalam pelaksanaan pembangunan ekowisata hanya sebagian saja yang ikut bergotong royong melakukan pembersihan di area mangrove dan pemberihan jalan menuju mangrove.

Masyarakat Kampung Mekar jaya sebagian ada yang membantu pekerjaan pembangunan mangrove dengan membantu membangun tempat duduk dibeberapa titik tertentu disepanjang area mangrove.

Dalam pengelolaan dan pengembangan mangrove Kampung Rawa Mekar Jaya masih terdapat kendala sehingga belum dapat memberikan manfaat yang optimal. Hambatan yang di hadapi oleh masyarakat yakni, keterbatasan pengetahuan masyarakat kampung Rawa Mekar Jaya dalam memanfaatkan potensi ekowisata magrove yang telah ada

\section{SARAN}




\begin{tabular}{|c|c|c|c|c|}
\hline Share: Social Work Jurnal & VOLUME: 10 & NOMOR: 1 & HALAMAN: $73-82$ & $\begin{array}{c}\text { ISSN: 2339-0042 (p) } \\
\text { ISSN: 2528-1577 }(e) \\
\text { DOI: 10.24198/share.v10i1.26896 }\end{array}$ \\
\hline
\end{tabular}

Partispasi masyarakat dalam pengelolaan mangrove di Kampung Rawa Mekar Jaya perlu dibina dan ditingkatkan dalam rangka meningkatkan kesejahteraan masyarakat dan lingkungan hidup yang hijau dan sehat.

Sumber biaya yang selama ini menjadi keluhan masyarakat, supaya kedepannya dipertimbangkan oleh pemerintah untuk menyalurkan bantuan dana bagi masyrakat yang berminat melakukan kreatifitas dalam kegiatan pengelolaan mangrove.

\section{DAFTAR PUSTAKA}

Afriza Lia, Kartika Tinting, Riyanti Anti. 2017. JSTP, Pengembangan Ekowisata Berbasis Masyarakat (Community Based Ecotourism) Dalam Rangka Mengentaskan Kemiskinan Di Desa Karangsong Kabupaten Indramayu. 3 (1): 20-34.

Cesario AE, dkk. 2015. Jurnal Sylva Lestari, Partisipasi Kelompok Masyarakat Dalam Pelestarian Hutan Mangrove Di Desa Margasari Kecamatan Labuhan Meringgai Kabupaten Lampung Timur. 3 (2): 21-30.

Dwiningrum, 2015. Desentralisasi dan partisipasi masyarakat dalam pendidkan. Yogyakarta : Pustaka Pelajar.

Fahrian, HH, dkk. 2015. . Biosaintifika Journal Of Biology \& Biology Education, Potensi Ekowisata Di Kawasan Mangrove Desa Mororejo Kabupaten Kedal. Volume 7. Nomor 2.

Hertati, Diana. 2017. Prosiding Seminar \& Call For Paper Fakultas IImu Sosial \& IImu Politik Universitas Muhammadiyah Sidoarjo, Pengembangan Ekowisata Hutan Mangrove Berbasis Masyarakat Di Wonorejo Surabaya.142-148.

Isbandi, Rukiminto, Adi. 2007. Perencanaan Partisipartoris Berbasis Aset Komunitas dari Pemikiran Menuju Penerapan, Depok: FISIP UI Press.

Mardikanto, Totok. 2013. Pemberdayaan Masyarakat dalam Perspektif Kebijakan Publik. Bandung: Alfabeta.

Manahampi RM, dkk. 2015. ASE, Peran Ekowisata Bagi Kesejahteraan
Masyarakat Bahoi Kecamatan Likupang Barat. $11(3 \mathrm{~A})$ : 1-18.

Maruf, Amar, dkk. 2018. Ecogreen, Persepsi Dan Sikap Masyarakat Terhadap Pengembangan Ekowisata Mangrove Bungkutoko Kendari. 4 (1): 43-51.

Nawawi, Ahmad. 2013. Jurnal Nasional Pariwisata, Partisipasi Masyarakat dalam Pengelolaan Wisata Pantai Depok di Desa Kretek Parangtritis. Volume 5, Nomor 2.

Nugraha, Bagus, dkk. 2015. Jurnal Sylva Lestari, Perencanaan Lanskap Ekowisata Hutan Mangrove Di Pantai Sari Ringgung Desa Sidodadi Kecamatan Padang Cermin Kabupaten Pesawaran. 3 (2): 53-56.

Saputra, SE \& Setiawan, Agus. 2014. . Jurnal Sylva Lestari, Potensi Ekowisata Hutan Mangrove Di Desa Merak Belantung Kecamatan Kalianda Kabupaten Lampung Selatan 2 (2): 49-60.

Selinaswati. (2017). Jurnal Socius, Partisipasi Masyarakat Dalam PembangunanEkowisata Sungai Pinang (Studi Kasus: Nagari Sungai Pinang Kecamatan Koto Ix Tarusan Kabupaten Pesisir Selatan Sumatera Barat) Vol. 4, No.2.

Siburian, Robert \& John Haba. 2016. Konservasi Mangrove Dan Kesejahteraan Masyarakat. Jakarta: Yayasan Pustaka Obor Indonesia.

Solekhan. $2006 . \quad$ Penyelenggaraan Pemerintahan Desa berbasis Partisipasi Masyarakat. Malang: setara press.

Sulistiyorini, N. R., Darwis, R. S., \& Gutama, A. S. (2015). SHARE: Social Work Journal, Partisipasi Masyarakat Dalam Pengelolaan Sampah Dilingkungan Margaluyu Kelurahan Cicurung. 5(1).

Syahyuti, 30 Konsep Penting Dalam Pembangunan Pedesaan dan Pertanian, Penjelasan tentang konsep, Istilah, teori, dan Indikator serta Variabel, PT. Bina Rena Pariwara, Jakarta,

Wibhawa, B., Raharjo. T., \&. Santoso, MB., 2010. Dasar-Dasar Pekerjaan Sosial. Bandung: Widya Padjadjaran. 


\begin{tabular}{|c|c|c|c|c|}
\hline Share: Social Work Jurnal & VOLUME: 10 & NOMOR: 1 & HALAMAN: $73-82$ & $\begin{array}{c}\text { ISSN: 2339-0042 (p) } \\
\text { ISSN: 2528-1577 }(e) \\
\text { DOI: 10.24198/share.v10i1.26896 }\end{array}$ \\
\hline
\end{tabular}

